\title{
EL MODERNISMO DE JOSÉ MARÍA VARGAS VILA
}

\author{
POR \\ Hugo Hernán Giraldo Castaño \\ Universidad Nacional de Colombia, Sede Medellín
}

In memoriam: Edgar Garavito

\section{INTRODUCCIÓN $^{1}$}

El presente estudio tiene como objeto resaltar la novedad de la obra del escritor colombiano José María Vargas Vila (1860-1933) en el contexto de la sociedad finisecular hispanoamericana. Esta novedad, aunque opacada por la crítica literaria colombiana que la valoró con desdén debido a su singularidad, fue reconocida por diferentes sectores sociales marginados de los círculos de poder. Los sectores obreros, artesanales, estudiantiles y algunos intelectuales de Hispanoamérica percibieron el carácter libertario de su escritura. Con el objeto de poner de relieve algunas de estas novedades a través de este ensayo desarrollo, por un lado, la singular manera en que Vargas Vila forja una obra en el contexto del Modernismo hispanoamericano generando así una de sus múltiples derivas que yo denomino "márgenes del Modernismo"; por el otro, expongo su contribución en la configuración de la Modernidad en Hispanoamérica; dentro de esta perspectiva desarrollo cuatro aspectos. En primer lugar, en relación con el aporte fundacional al mercado literario; en segundo lugar, a través de la instauración de una máquina literaria que conecta la enunciación individual con el campo político; en tercer lugar, a través de la problematización del lenguaje como asunto de poder, y en cuarto lugar, por medio de la promoción de la secularización y el ateísmo. A través de estos aspectos justifico la hipótesis de que Vargas Vila es uno de los escritores modernistas hispanoamericanos con el merito de haber asumido su más vehemente batalla en defensa de uno de los rostros de la Modernidad, el rostro luminoso de las transformaciones culturales; desde esta perspectiva fustigó la faz oscura de la modernidad: la de las cárceles, la censura y

\footnotetext{
1 Este texto es producto de una investigación realizada sobre las ideas éticas, estéticas y políticas de José María Vargas Vila, en la Universidad Nacional de Colombia, Sede Medellín, para optar al título de historiador.
} 
la represión liderada por los ideólogos de la hegemonía conservadora colombiana. En aras de contextualizar esta problemática recordemos con Michel Foucault que, a fines del siglo XVIII: "Las Luces, que han descubierto las libertades, inventaron también las disciplinas" (Vigilar 225).

\section{Desde los márgenes del Modernismo}

José María Vargas Vila fue un prolífico escritor que produjo una obra heterogénea y extensa caracterizada por la pasión por la libertad y el arte. Esta doble pasión produjo efectos por doquier, hasta tal punto que ha polarizado a la crítica literaria, que oscila entre quienes prefieren olvidarla o quienes la reivindican; entre los primeros, se encuentra un amplio grupo que bien podría ser representado por Gustavo Cobo Borda o Malcolm Deas, quienes -aunque han escrito diferentes ensayos sobre el escritor-han reconocido su desdén por la obra, y entre los segundos, se encuentran académicos que como Arturo Escobar Uribe y Consuelo Triviño han emprendido una lectura crítica.

Con la expresión "Vargas Vila, desde los márgenes del Modernismo" queremos poner de relieve la singularidad del escritor colombiano al interior del principal movimiento estético hispanoamericano: el Modernismo. Así exploraremos una deriva singular del movimiento; una de las tantas expresiones polifónicas del Modernismo, la más política y de mayor efecto en el campo sociocultural del continente. Resalto el aspecto de "márgenes del Modernismo" porque este escritor nómada en la vida y en la obra deambuló entre fronteras territoriales y estéticas. A nivel territorial osciló entre el continente americano y europeo, y a nivel literario desplegó una escritura en las fronteras entre el Romanticismo y el Modernismo, aquel Romanticismo definido por Víctor Hugo como liberalismo en literatura, y aquel Modernismo caracterizado por Rubén Darío como estética sin normas. En esas fronteras Vargas Vila se movió con absoluta soberanía, desplegando su pasión por la libertad y el arte, dos de los grandes ideales que articulan estas escuelas. Así, su obra entre la de los modernistas es singular, marginal. Esta situación ha incidido para que entre los estudios canónicos sobre el Modernismo colombiano no se le haya tenido en cuenta. El predominio de este tipo de miradas monolíticas del Modernismo que aún prevalece va en contra de la realidad del movimiento, que debe entenderse como polifónica y de mayor complejidad. Así lo han corroborado estudios recientes del movimiento que indican, entre otras cosas, que "dentro de la noción de modernismo se encierra una multiplicidad de manifestaciones que, siendo muchas veces dispares, de alguna manera lo configuran: no hay un modernismo, hay una pluralidad de modernismos, de amplias vías abiertas dentro de un cauce común" (Oviedo 218).

Vargas Vila exploró una dimensión política del Modernismo, con la voluntad de transgresión que lo caracterizó siempre mantuvo una actitud de contraste con las escuelas estéticas canonizadas; el autor combinó con absoluta libertad tópicos realistas, románticos

Revista Iberoamericana, Vol. LXXXI, Núm. 252, Julio-Septiembre 2015, 787-803 ISSN 0034-9631 (Impreso)

ISSN 2154-4794 (Electrónico) 
y decadentes hasta cristalizar un peculiar estilo modernista que lo escindió del grupo elogiado por todos. En su pasión escritural explora una prosa plenamente modernista en su estilo, que se caracteriza por la solemnidad en la escritura, mutilaciones de la sintaxis en beneficio del efecto, elección de las palabras por su sonoridad, su ritmo y su colorido. El Modernismo también se expresa en los temas y problemas que explora: cosmopolitismo, exotismo, individualismo, esteticismo, o escepticismo. Sin embargo, en su tiempo y en el nuestro, se le ubicó al margen de las celebridades y la crítica siempre lo situó como un caso atípico del movimiento, como lo expresó Juan Ramón Jiménez:

Aquel vacío pedante de Vargas Vila, le dijo una vez a Rubén Darío, delante de mí: "Rubén, tú eres el sol de Nicaragua, yo el de Colombia. Cuando yo no soy Vargas Vila, soy d'Annunzio; cuando tú no eres Rubén Darío, eres Víctor Hugo.” En todo caso, Rubén Darío era mi sol, era el sol de Nicaragua y de muchos muchachos y países más. Y aquel sol fue de aurora para los españoles, y esa aurora venía, nadie lo dudaba, fuera por donde fuera, de la América de nuestra lengua. (233)

Vargas Vila tuvo el mérito de ser uno de los escritores de fines de siglo que liderara, junto con José Martí, el ala política del Modernismo. A través de su escritura encabezó una actitud crítica con la sociedad de su tiempo, con lo cual asumió una actitud de modernidad, conduciéndolo a la promoción de la ideología de la Ilustración europea que en Hispanoamérica se concretó a través del proyecto del liberalismo radical colombiano de mediados de siglo. En obras como Pretéritas, Los Divinos y los Humanos, Los Césares de la decadencia y Ante los bárbaros, su prosa demoledora emerge con gran furor en la defensa de la democracia, la secularización, la crítica de las dictaduras, la religión y el expansionismo norteamericano. La suma de estas características dibuja claramente la imagen de Vargas Vila como un escritor que cumplió con rigor la función de intelectual en Hispanoamérica. El compromiso político de la escritura le valió el reconocimiento de grandes figuras de las letras. Al escritor francés Anatole France se le ha atribuido el siguiente juicio: "A este hombre, Vargas Vila, flor medrosa de la lejana Colombia, no le falta más que una cosa para sentarse a la diestra de nuestro padre Hugo: Haber nacido en Francia" (citado en Arciniegas 3). Su amigo y cómplice en la lucha por la defensa de la democracia en el continente, José Martí, le escribe:

Yo le amo a usted la palabra rebelde y americana como hoja de acero con puño hecho a cincel, con que cruza las espaldas sumisas o los labios mentirosos: yo le amo la hermandad con que se liga usted, en este siglo de construcción y pelea, con los que compadecen y sirven al hombre, contra los que lo encapotan y oprimen: yo le amo la perspicacia y ternura con que miró usted, en la fuente de toda mi energía que es la piedad infatigable de mi corazón. (448-449)

Revista Iberoamericana, Vol. LXXXI, Núm. 252, Julio-Septiembre 2015, 787-803 ISSN 0034-9631 (Impreso)

ISSN 2154-4794 (Electrónico) 
El más consentido de los modernistas, Rubén Darío, con quien sostuvo una relación de complicidad hasta su muerte y sobre el que escribió un libro en su memoria que elogian hasta sus detractores, nos dejó su imagen, en la cual se hace explícita la singularidad del escritor quién desde su exilio y soledad en Europa estimulaba el fragor de la resistencia y el debate en Hispanoamérica. En ese libro, titulado Rubén Darío (1917), Vargas Vila consigna los versos que el nicaragüense le regalara:

\section{VARGAS VILA, señor de rayos y de leones, callado y solitario recorre las ciudades, y ninguno alimenta rebaño de ilusiones, como este luminoso Pastor de Tempestades. (74)}

Vargas Vila realizó un aporte fundamental en el proceso de configuración de la modernidad en Hispanoamérica. Esta apuesta la realizó de la mano de sus amigos y cómplices de tantas batallas en pro de la libertad y el arte como José Martí y Rubén Darío, por sólo citar dos nombres de esa heterogeneidad de escritores modernistas que forjaron en cuerpo y espíritu una nueva imagen de la América libre en su lengua y en su territorio.

Con Vargas Vila las letras hispanoamericanas asumen plena autonomía en la exploración del ser del lenguaje y la problematización sobre el pasado y el futuro del continente. De esta manera, el movimiento estético modernista trascendió el aspecto formal para problematizar la actualidad en toda su complejidad. No se puede olvidar que los escritores modernistas no sólo escribían versos hermosos, sino que también se ganaban el pan escribiendo crónicas en los periódicos hispanoamericanos y europeos; y precisamente, a través de estos escritos en prosa irradiaron por todo el continente gran variedad de ideas que terminaron transformando la atmósfera sociocultural del continente. Poco a poco la historiografía literaria elucida cuanto le debe la Modernidad hispanoamericana a la generación de utópicos modernistas. Hoy sí sabemos cuánto les costó a ellos este sueño americano: la muerte temprana de José Martí, el suicidio de José Asunción Silva, la bohemia de Rubén Darío, el exilio y la soledad de Vargas Vila. He ahí el costo en carne y sangre de una generación utópica que se la jugó por la libertad del lenguaje y la libertad política. La apuesta por una lengua libre, abierta a nuevas expresiones y una sociedad democrática, autónoma, libre de despotismos políticos, es la que poco a poco se le reconoce a los modernistas. Estos fueron autores que hicieron posible la segunda independencia: la de la imaginación, del lenguaje y del pensamiento.

\section{LA APUESTA POR LA MODERNIDAD}

La Modernidad es una problemática compleja, máxime cuando en tiempos en que se anuncia el fin de su utopía a través del pensamiento postmoderno sus proyectos

Revista Iberoamericana, Vol. LXXXI, Núm. 252, Julio-Septiembre 2015, 787-803 ISSN 0034-9631 (Impreso)

ISSN 2154-4794 (Electrónico) 
siguen dando qué pensar. Esta situación incide radicalmente para que haya necesidad de hablar de modernidades debido a la heterogeneidad de problemáticas que involucra y a la diversidad de países, de uno y otro lado del Atlántico, que hicieron parte de este proceso, además de las disímiles formas de concreción histórica que ha tenido espaciotemporalmente. Estas circunstancias han incidido para que sea difícil caracterizar la Modernidad. Sin embargo, en el contexto de este escrito resalto la Modernidad como período histórico y como actitud crítica del presente. Como período histórico, con el nombre de modernidad hacemos referencia al quiebre histórico que experimentan las sociedades occidentales de fines del siglo XVIII producto de complejos procesos de transformación social, política, económica y cultural, los cuales hicieron posible las revoluciones burguesas -la Revolución Norteamericana (1776), la Revolución Francesa (1789), incluyendo las revoluciones pro-independentistas de Hispanoamérica- y la Revolución Industrial Inglesa (1760). Esta amplia y compleja dinámica sociocultural fue estimulada por el proyecto de la Enciclopedia dirigido por Jean le Rond d'Alembert (1717-1783) y Denis Diderot (1713-1784), quienes divulgaron las novedades de la revolución científica y del pensamiento filosófico. Por estas circunstancias este amplio movimiento recibió el nombre, ora de la Ilustración, ora del Siglo de las Luces. Luis Miguel Enciso en su estudio sobre la Europa del siglo XVIII ha precisado:

La Ilustración se entiende mejor si se la considera, no como un sistema de ideas, y menos como una ideología, sino como una actitud capaz de transformar el hombre y el mundo que lo rodea. El fundamento de tal actitud se encuentra en definiciones de época, como el sapere aude kantiano, el osez penser volteriano o el propio entendimiento de Feijoo, y se expresa, sobre todo, a través de tres postulados: la fe en la capacidad creativa y transfiguradora de los saberes, el respeto crítico -y a veces, el ataque- a la fe cristiana y el afán de reformas. (266)

La Modernidad, además de ser un período histórico que instaura una ruptura con el antiguo régimen, propicia una nueva época en la que se configuran los Estados nacionales occidentales -entre ellos los de Hispanoamérica como producto de las revoluciones de independencia-, la secularización de la sociedad y la economía capitalista. También es posible concebir la Modernidad como una actitud crítica con el presente, Michel Foucault encuentra la perfilación de esa actitud moderna en dos autores que desde el epicentro de la modernidad pensaron su propia actualidad: Immanuel Kant y Charles Baudelaire. En la respuesta que Kant da en 1784 a la pregunta “¿Qué es la Ilustración?”, define la Ilustración como una salida del estado de "minoría de edad", y por "minoría de edad" entiende la aceptación de la autoridad de otro en la conducción de los dominios en los que es conveniente hacer uso de la razón (1). Esta salida es caracterizada por Kant como un proceso que se está desarrollando y como una tarea que hay que asumir. Para Foucault la novedad del texto sobre la Ilustración de Kant es que introduce una

Revista Iberoamericana, Vol. LXXXI, Núm. 252, Julio-Septiembre 2015, 787-803 ISSN 0034-9631 (Impreso)

ISSN 2154-4794 (Electrónico) 
reflexión crítica sobre el presente, a través de la promoción del uso público de la razón, además de situar su trabajo en relación a dicho contexto, según Foucault:

Es la primera vez que un filósofo enlaza de esta manera, estrechamente y desde el interior, la significación de su obra con relación al acontecimiento, una reflexión sobre la historia y un análisis particular del momento singular en el que escribe y a causa del que escribe. La reflexión sobre el "hoy" como diferencia en la historia y como motivo para una tarea filosófica particular es, en mi opinión, la novedad de este texto. Y considerándolo así, estimo que se puede reconocer en él un punto de partida: el esbozo de lo que se podría llamar la actitud de modernidad. (Estética 341)

Desde otro contexto, Charles Baudelaire, líder de la modernidad estética, y quién junto con Gustav Flaubert configuró, en términos de Pierre Bourdieu, la autonomía del campo literario, realizó una serie de reflexiones agudas sobre la Modernidad. Sobre el hombre de la modernidad, escribe Baudelaire:

Va, corre, busca. Sin duda, este hombre, este solitario dotado de una imaginación activa, que viaja siempre a través del gran desierto de los hombres, tiene una mirada más alta que el de un puro paseante (flâneur), una meta más general, distinta del placer fugitivo de la circunstancia. Busca ese algo que, si se nos permite, llamaremos la modernidad. Para él, se trata de extraer de la moda aquello que puede contener de poético en lo histórico. (677)

Para Foucault, la importancia de la reflexión baudelaireana sobre la modernidad consiste en que allí ve de nuevo la promoción de una actitud que toma en serio su tiempo, el presente, con el objeto de transformarlo; con lo cual queda esbozada la Modernidad como actitud crítica. "La modernidad baudelaireana es un ejercicio en el que la extrema atención a lo real se confronta con la práctica de una libertad que al mismo tiempo respeta eso real y lo viola" (Estética 344).

En el contexto hispanoamericano, Vargas Vila es uno de los escritores modernistas que asume la reivindicación de la Modernidad. Este proceso lo asume de dos maneras: promoviendo los presupuestos culturales de la Ilustración y asumiendo una actitud crítica contra los sistemas de gobierno que se enmascaran en la defensa del orden, la tradición, el lenguaje y la religión, para desplegar sus dispositivos restrictivos a las libertades de los pueblos. Con el objeto de poner de relieve la manera como Vargas Vila, desde los márgenes del Modernismo, se enfrentó a la actitud de "contramodernidad" liderada por los ideólogos de la Regeneración, y para mostrar cómo contribuyó en la configuración de la modernidad en Colombia, resalto cuatro aspectos: el aspecto fundacional, la escritura como enunciación colectiva, el lenguaje como problema político y la divulgación de la muerte de Dios.

Revista Iberoamericana, Vol. LXXXI, Núm. 252, Julio-Septiembre 2015, 787-803 ISSN 0034-9631 (Impreso)

ISSN 2154-4794 (Electrónico) 
Alos modernistas se les reconoce el aporte fundacional de las letras hispanoamericanas en tres aspectos significativos. En primer lugar, la consolidación de los medios de expresión, un proceso al que Vargas Vila aportó considerablemente a través de la fundación de periódicos y revistas. En Venezuela, inició la revista Eco Andino, Los Refractarios, y el periódico La Federación. En Nueva York, el diario El Progreso y las revistas Hispanoamérica y Némesis, esta última editada intermitentemente hasta la tercera década del siglo XX. En segundo lugar, a la profesionalización del escritor como consecuencia de la apertura del mercado literario que le permitía vivir de su oficio y evadir el mecenazgo político. Es una afirmación repetida que Vargas Vila fue el primer escritor colombiano, antes de García Márquez, que se dio el lujo de vivir de su escritura. Dos editoriales importantes de Europa lo publicaron-además, de las copiosas ediciones que de manera no autorizada se hicieron en Hispanoamérica-la editorial española Ramón Sopena y la francesa Vda. de Bouret. En tercer lugar, la formación y ampliación de un público lector. En Hispanoamérica abundan los testimonios del aporte que Vargas Vila hizo en este sentido. Muchos lectores, no necesariamente intelectuales todos ellos, se formaron al calor de las ideas libertarias, transgresoras y anticlericales del colombiano. Aníbal Noguera Mendoza ha explorado ampliamente este aspecto y concluye que "Vargas Vila era el más leído escritor de la lengua española nacido en América” (322). Por su parte, en su perfil de Vargas Vila, Ebel Botero escribió:

Su estilo ha cautivado a 50 millones (o más) de lectores hipersensibles. Y con razón, porque es vigoroso y grandilocuente, lleno de contrastes huguescos y de antítesis donoso-cortesianas, bíblico en los paralelismos, experto en el claroscuro, y como si fuera poco, lapidario y rítmico, sonoro y aplastante. (96)

La escritura de Vargas Vila cumplió la función de agenciamiento colectivo de enunciación. El término lo tomo de Gilles Deleuze y Félix Guattari y con él resalto el aspecto político de una escritura que logra generar grandes efectos en el contexto social hispanoamericano debido a la manera que se conecta con el imaginario colectivo de la sociedad a través de la exploración de temas y problemas reprimidos socialmente. Este autor terminó instaurando una verdadera máquina de perturbación discursiva al interior de los diferentes géneros literarios. Es así como pocos críticos soportan esas obras discontinuas, fragmentarias y con excesivas digresiones políticas, motivo por el cual las instituciones sociales y académicas no dejaron de censurar esta obra. Como ejemplo conviene citar al historiador inglés Malcolm Deas, quien a finales del siglo XX, aún hacía eco de la resistencia que ideólogos del proyecto regenerador en Colombia, de comienzos de siglo, sentían por Vargas Vila: "Después de leerlo por un par de días, cualquier lector debe estar de acuerdo con el general Reyes, en que 'hay que desvargasvilizar a Colombia'. Siendo el caso que su influencia se extiende por muchas otras partes, mejor decir que hay que desvargasvilizar a América Latina” (7).

Revista Iberoamericana, Vol. LXXXI, Núm. 252, Julio-Septiembre 2015, 787-803 ISSN 0034-9631 (Impreso)

ISSN 2154-4794 (Electrónico) 
La escritura vargasviliana no se despliega lógica, coherente y sistemáticamente a la manera de una escritura hegemónica, al contrario, lo hace fragmentariamente y así conecta el erotismo y la política: lo privado y lo público. Este autor que valora la escritura desde la perspectiva de la libertad que defiende, recrea temáticas que hacen sacudir la tradición al promover contra-valores. Así, sus héroes y heroínas encarnan ideales transgresores al asumir y promover una vida en continua confrontación con los valores religiosos y sociales a través del tratamiento de cuestiones como el adulterio, el suicidio, el homicidio, el escepticismo y el ateísmo. Las apreciaciones criticas de Jesús M. Ruano, uno de los jesuitas que asumieron la tarea de evaluar qué se podía o no leer durante la primera mitad del siglo XX en Colombia, son sintomáticas de las reacciones que provocaba Vargas Vila:

Por oficio y haciéndome dolorosa violencia he tenido que hojear los escritos vargasvilescos; y ... iqué horror!, qué modo de hozar en el cieno de la lascivia ... pero señor, me pregunto: ¡y ésto se lee! ¿Y esto se vende? ¿No hay otro sitio más noble ni más lúcido que el lupanar y el fango? ¿Más quién habla de belleza literaria en obras como Flor de Fango, Ibis, Rosas de la Tarde, La Simiente...? (citado en Escobar Uribe 75)

Como ha sido corroborado en una gran heterogeneidad de estudios, el ambiente cultural colombiano del período de la hegemonía conservadora era reaccionario a cualquier novedad; por tanto, la cultura colombiana de la época era de viñeta, según la caracterización del filólogo Rafael Gutiérrez Girardot: "En esta cultura señorial y de viñeta se dio a la mediocridad el valor de grandeza, y al sustituto torpe de la cultura originaria se lo consideró como creación superior a su modelo" (Modernismo 451). El gran mérito de Vargas Vila fue contribuir en el agrietamiento de esa tradición a través de una escritura heterodoxa que asumía la transgresión de lo divino y lo humano utilizando como uno de sus medios de expresión la novela, uno de los géneros literarios más subvalorados en el país. Según Raymond L. Williams “[e]n Colombia la novela siempre ha sido considerada un género menor. La élite dominante de hombres letrados ha cultivado históricamente la poesía y el ensayo como géneros ideales" (41). Este autor sustenta también que los prejuicios históricos contra la novela obedecen a que la elite siempre considera más apropiada la poesía como medio pedagógico para propagar su cosmovisión, o en el caso de utilizar la novela como género literario, siempre se utilizó como medio para divulgar su ideología conservadora.

La literatura buscaba pues varios objetivos a comienzos del siglo XX, y las novelas aceptadas oficialmente conllevaban un proyecto ideológico y moral. Por eso, los escritos de Suárez, Sánchez Gómez y Samper Ortega aparecieron con frecuencia en publicaciones oficiales. No los del polémico Vargas Vila. (Williams 64)

Revista Iberoamericana, Vol. LXXXI, Núm. 252, Julio-Septiembre 2015, 787-803 ISSN 0034-9631 (Impreso) 
Taly como lo indican diferentes testimonios, de los cuales ha dado cuenta ampliamente Aníbal Noguera Mendoza, otro hecho que corrobora la manera que la obra de Vargas Vila cumplió la función de agenciamiento colectivo de enunciación es la alta recepción de su obra en Colombia y en Hispanoamérica a través de diversas y numerosas ediciones autorizadas y piratas. A este respecto Luis Vidales afirma:

Que José María Vargas Vila es un publicista de la oposición nacional, lo comprueba la extensa aceptación de su obra en los medios del país en que el clamor por la libertad, la justicia y el pan es más ardido. Preguntad a cualquier viejo artesano de dónde se nutrió su espíritu revolucionario, un tanto vago pero inamovible, e invariablemente os dirá que su primer maestro fue Vargas Vila. (669)

En este contexto Vargas Vila escribió: "La literatura no fue para mí sino un vehículo de mis ideas, y fue en ese sentido que yo escribí novelas y juicios críticos y libros de estética pura. Yo no quiero ser desnudado de mis arreos de combatiente, ni aun en el fondo del sepulcro. Como un caballero medieval quiero ser enterrado con mis armas" (Diario secreto 108).

La escritura vargasviliana se conectó fácilmente con una multiplicidad de voces indiscernibles que procedían de diferentes pueblos hispanoamericanos a los que a fuerza de adoctrinamiento religioso y despotismos políticos les habían impedido expresarse. Esta escritura centrípeta facilitó un tipo de denuncia colectiva de carácter político y terminó instalando una verdadera máquina de guerra al interior de los géneros literarios, ya que cualquier género era adecuado para enunciar y denunciar las diferentes maneras en que el cuerpo de la población era reducido a las peores miserias existenciales. Así, esta escritura se constituyó simultáneamente en el embrión de una futura máquina revolucionaria en tanto no dejaba de promover por diferentes medios la utopía de la libertad. Existen testimonios, entre otros de José Vasconcelos, quién en sus memorias referenciadas por Aníbal Noguera Mendoza, da cuenta de la presencia de Vargas Vila en la Revolución Mexicana: "Se ha dicho que los coroneles de la revolución no conocieron otro maestro" (314).

La vertiente textual de Vargas Vila penetrada por la pasión por la libertad como fuerza inmanente terminó problematizando el modelo estándar que imponían las literaturas mayores en Colombia. En una sociedad como la colombiana de finales del siglo XIX y primeras décadas del XX, en la cual la educación pública y la formación cultural estuvieron orientadas por la Iglesia, no es muy difícil sospechar que las literaturas que se erigieron como modelos fueron aquellas que mejor pudieron interpretar los gustos e intereses dominantes. Esta situación permite comprender la accidentada recepción de las ideas modernas en Colombia y la importancia de la obra de Vargas Vila que, con sus temas heterodoxos, anticlericales y transgresores estimuló la resistencia social: “¿que el agnosticismo de mis libros, siembra la desolación en los espíritus y, los hace inermes

Revista Iberoamericana, Vol. LXXXI, Núm. 252, Julio-Septiembre 2015, 787-803 ISSN 0034-9631 (Impreso)

ISSN 2154-4794 (Electrónico) 
para toda forma de esfuerzo pecórico, es decir, de sacrificio?/ y, ¿qué Crimen es ese de desidiotizar las almas fieras, volviéndolas á su terrible actitud de almas heroicas?" (Huerto agnóstico X).

En los estudios culturales colombianos del período de la hegemonía conservadora predomina un espíritu como el descrito por el filósofo Rubén Sierra Mejía, quien expresa que "el siglo XX en filosofía y en el plano del pensamiento teórico, como en muchas otras cosas entre nosotros, prolonga el siglo XIX, hasta una fecha cercana a 1930" (91). En el mismo sentido a la hora de caracterizar el ámbito sociocultural colombiano de la primera mitad del siglo XX, Luis Antonio Restrepo argumenta que "no es pues exagerado definir la cultura de la época como una 'cultura de sacristía'. Ciertamente una minoría resistió, pero la mayoría se adhirió por convicción o por interés" (67). En este contexto Vargas Vila despliega su apasionada escritura erigiéndose como un adalid, por lo menos al nivel textual, de la Modernidad en la Colombia finisecular. Su mayor obsesión fue hacer estallar la sociedad que, consagrada al Corazón de Jesús, se alejaba del proceso secularizador, y se apartaba de la imperativa necesidad de asumir con sentido crítico su actualidad. A este respecto afirma Vargas Vila:

Si la Ética Teológica ha caído por sus bases, es porque la idea de Dios tiende a disminuir en los hombres; / las sociedades, se laicizan sin libertarse, y declarándose herederas de Dios, toman todos sus medios de dominación, de ahí que, a la Moral de origen divino, haya sucedido la Moral de origen humano, es decir, la Moral Social, la más absurda de todas y la más absoluta. (Del rosal 53)

La escritura de Vargas Vila no fue ajena a una de las problemáticas más importantes en la Modernidad: el lenguaje. La problematización la inició Federico Nietzsche a través de su proyecto genealógico de demolición de la metafísica occidental: 'La 'razón' en el lenguaje: ¡oh, qué vieja hembra engañadora! Temo que no vamos a desembarazarnos de Dios porque continuamos creyendo en la gramática" (55); y la continuó Vargas Vila en la Hispanoamérica finisecular con afirmaciones como aquella de que "sin una lengua libre, no puede haber un pensamiento libre; y, él, escribió con verbo libre, sus libros, tan libres como su Verbo" (Ars Verba 130). Esta línea de pensamiento se continúa más recientemente a través de una heterogeneidad de escritores, entre los que conviene resaltar a Roland Barthes, quién en su lección inaugural en el Collège de France a mediados de los años setenta planteó que "la lengua, como ejecución de todo lenguaje, no es ni reaccionaria ni progresista, es simplemente fascista, ya que el fascismo no consiste en impedir decir, sino en obligar a decir" (120). La contextualización de esta problemática quizás hace comprensible el nivel de importancia que para la sociedad hispanoamericana de entresiglos significó la máquina de guerra que Vargas Vila desplegó al interior de los diferentes géneros discursivos. 
Aunque el escritor colombiano conoció varias lenguas: el inglés, el francés, el latín y el italiano, sólo escribió en castellano. A lo largo del proceso de conquista y colonización llevado a cabo por el imperio español en el continente americano desde principios del siglo XVI, el castellano fue impuesto hegemónicamente y redujo a simples dialectos la diversidad de lenguas precolombinas. A través del castellano se impuso la hegemonía pues esta lengua cumplió la función de medio de comunicación, de lengua de intercambio comercial, de transmisión burocrática, de control social, lo mismo que una función de lengua referencial que marcaba lo que era considerado como cultura válida en Hispanoamérica. Aunque el uso del castellano le permitió a Vargas Vila conectarse con una basta población, su pasión por la libertad le hizo imposible la sumisión al metro-patrón de esa lengua hegemónica. La necesidad de diferencia lo llevó a la tarea de emprender un proceso de problematización de la lengua: "Se me acusa de impresionismo porque uso un lenguaje mío, que no se amolda ni al gusto, ni a las reglas de todos; yo, domino el lenguaje; no entiendo que el lenguaje me domine" (De los viñedos 99).

La obra de Vargas Vila asume una serie de batallas contra las instituciones sociales, a través de las cuales el ejercicio del poder se enmascaraba y se ejercía a nombre de la moral y del lenguaje. Hablando de sí mismo en tercera persona reclama que

\begin{abstract}
Vargas Vila, ha declarado altamente no aceptar y no seguir las reglas estrechas de la academia: como no acepta y no sigue los dogmas estrechos de las iglesias; / ni academias, ni concilios le dan la ley; / tanto vale para él la Academia como el Sylabus; / y, se cuida tanto de la inmutabilidad del idioma como la inviolabilidad del dogma; / . . y, tiene sin embargo, la grata entretención, de violar por igual los dogmas y las frases, torturar la fe y el lenguaje, con una rara voluptuosidad, que le viene de su amor huraño á la independencia del espíritu. (Laureles 31)
\end{abstract}

Así, la Iglesia y las academias de la lengua fueron su blanco predilecto. En Los estetas de Teópolis (1918), en clara alusión a su país y al ámbito hispanoamericano, Vargas Vila afirma que "en Teópolis, la Gramática, es el cuarto Dios, y, es el único Talento del Noventa por Ciento de nuestros escritores; / en Teópolis, respetamos la Gramática todos, hasta los cocheros; recientemente uno de ellos, que era mozo de cuadra, ha surgido a la celebridad por haber escrito un cuento ñoño, en lenguaje de hace tres siglos, que es nuestro gran lenguaje" (18). Este fustigamiento no era en vano ya que en la sociedad colombiana de la hegemonía conservadora la religión, la gramática y el poder alcanzaban el umbral de lo indiscernible. Los clérigos desde el púlpito elegían presidentes, y gramáticos como Caro, Cuervo, Marroquín o Suárez eran verdaderos hombres de poder, tal y como lo precisa Malcolm Deas:

Revista Iberoamericana, Vol. LXXXI, Núm. 252, Julio-Septiembre 2015, 787-803 ISSN 0034-9631 (Impreso)

ISSN 2154-4794 (Electrónico) 
Para los letrados, para los burócratas, el idioma correcto es parte significativa del gobierno. La burocracia imperial española fue una de las más importantes que el mundo haya jamás visto, y no es sorprendente que los descendientes de esos burócratas no lo olvidaran; por eso, para ellos lenguaje y poder deberían permanecer inseparables. ... El dominio del idioma llegó a ser y lo fue durante mucho tiempo, elemento del poder político. Núñez se sirvió de él, como Caro y Marco Fidel Suárez. (Del poder 42)

Vargas Vila exploró con pasión esta problemática de lenguaje y poder a través del tratamiento del lenguaje en su escritura por un lado, y por el otro también en el ámbito de su contenido. Es por eso que lo introduce regularmente en cualquier género literario. En la novela Los parias (1903) el autor caracteriza de la siguiente manera al presidente de la República:

un retórico vil, escapado a los tugurios de Bizancio, reinaba sobre aquel pueblo vencido, con la ultrajante insolencia de un esclavo hecho Rey; / Aquel gramático pedante y nulo, ebrio de latín, ensayaba el manto de púrpura y la corona imperial, bajo aquel solio sombrío, de donde un tigre lírico, acababa de desaparecer, arrebatado por la muerte (144)

La escritura vargasviliana dirigió su artillería frente al poder que se ejercía en nombre de la tradición, en la cual religión y lenguaje jugaban un papel importante, pero no conforme con las municiones que la tradición le ofrecía, se aventuró a experimentar con el viejo material con el objeto de crear nuevas y más eficaces metrallas. Fue así como su arma, la pluma, pudo contar con una nueva forma, heredera del castellano pero parcialmente diferente, que le ofrecía nuevas posibilidades de expresión: "mi prosa, no es hecha de melodías, sino de rebeldías: / no es prosa de debate; es prosa de combate; / mi Verbo, no es una lira; / mi Verbo, es una espada" (Ars Verba 240).

Pretender hacer de la pluma, esto es, del lenguaje, algo tan eficaz como una espada o la artillería de un ejército para combatir el autoritarismo es inusitado en el uso de la lengua, precisamente por eso esta escritura se vio comprometida a un proceso de forzamiento. En este proceso Vargas Vila perfiló como su mejor aliado el uso del adjetivo: "Amo la verdad, con un amor de artista. / Pinto los hombres y los acontecimientos con fidelidad gráfica; pongo un adjetivo como clavara un dardo, siempre con justicia; y, como dijo el otro, no acostumbro hacer doblegar las palabras en que creo" (Los Divinos 11; énfasis en el original).

Un fragmento frecuentemente citado permite una aproximación a la singular manera en que Vargas Vila caracterizaba personajes políticos, literarios y críticos. Con motivo de la conmutación de la pena de muerte que un dictador centroamericano le concediera al poeta peruano José Santos Chocano, Vargas Vila escribe: "Los dioses no consintieron que Santos Chocano deshonrara el patíbulo muriendo en él; ahí está vivo, después de haber fatigado la infamia" (citado en Borges 157). Jorge Luis Borges al leer esta imprecación escribió:

Revista Iberoamericana, Vol. LXXXI, Núm. 252, Julio-Septiembre 2015, 787-803 ISSN 0034-9631 (Impreso) ISSN 2154-4794 (Electrónico) 
es la injuria más espléndida que conozco. ... Deshonrar el patíbulo. Fatigar la infamia. A fuerza de abstracciones ilustres la fulminación descargada por Vargas Vila rehúsa cualquier trato con el paciente y le deja ileso, inverosímil, muy secundario y posiblemente inmoral. Basta la mención más fugaz del nombre de Chocano para que alguno reconstruya la imprecación, oscureciendo con maligno esplendor todo cuanto a él se refiere -hasta los pormenores y los síntomas de esa infamia. (157)

Ahora bien, para hacer posible una nueva expresión, la escritura vargasviliana constriñe la lengua hegemónica a través de la desmesura y otras estrategias que facilitan el desbordamiento de las constantes gramaticales y morfológicas. Como ya ha sido señalado por otros críticos, algunas de esas estrategias incluyen la sustitución del punto seguido y del punto final por el punto y coma, la utilización de mayúsculas para enfatizar términos, aun cuando el correcto uso de la lengua lo prohibiera, y el uso frecuente de figuras estilísticas complejas como la conjunción, la anáfora, la aliteración, la reticencia o la sinestesia. Con base en este procedimiento, y gracias a estos recursos, Vargas Vila hace posible una nueva expresión que era casi imposible en la lengua tradicional, esto es, articular la sensibilidad poética que lo caracteriza con el compromiso de las ideas libertarias inscritas en la prosa. De este modo hace posible una prosa-poemática, en la cual la prosa gana en ritmo y el verso en ideas. Gracias al predominio de las conjunciones y especialmente de la conjunción " $y$ ", además de la presencia de puntos suspensivos y la sobrecarga de imágenes, hay un pronunciado estímulo de la imaginación y de velocidad en la lectura. Sobre este aspecto recordemos la apreciación de Rubén Darío: "Vargas Vila, el célebre pensador, novelista y panfletista político, para mí no es sino, juntándolo todo, un único e inconfundible poeta, quizá contra su propia voluntad y autoconocimiento" (110).

La escritura de Vargas Vila utiliza otro nivel estratégico que interviene en la eficacia y la contundencia de la expresión para convertirla en artillería. Para lograrlo recurre a elementos estilísticos como el epíteto adjetival, el apóstrofe, el retruécano, la exclamación, la interrogación retórica, la antítesis, la paradoja, la ironía y el sarcasmo. A través de estos recursos su escritura deviene intensiva y demoledora. Como se observa en un fragmento en que Vargas Vila caracteriza al filólogo e ideólogo de la Regeneración colombiana Miguel Antonio Caro, el lenguaje tiene la posibilidad de perder el carácter representativo que el uso tradicional reivindica, y se constituye en verdadera artillería: "hay dos cosas inseparables de él: la Tiranía y la Gramática; / y, hay dos cosas que le son absolutamente imposibles: hacer un buen gobierno, y un buen verso; / sus actos, como sus rimas, son igualmente despóticos y áridos; / no ha tenido sino una voluptuosidad en su vida: violar las Musas; / y, las tiene ya domesticadas á su caricia brutal" (Los Césares 69). Para hacer posible esta escritura agitada y tempestuosa, que produce aniquilaciones inmediatas y locales, se debió recurrir al legado que la tradición ofrecía, pero utilizándolos de otra manera e introduciéndoles una nueva potencia, lo que permitió que fueran devueltos

Revista Iberoamericana, Vo1. LXXXI, Núm. 252, Julio-Septiembre 2015, 787-803 
en su contra, haciendo posible así el desborde de la lengua de poder y en consecuencia el agrietamiento de la tradición.

La muerte de Dios fue otro de los acontecimientos característicos de la Modernidad. La noticia la propagó el filósofo alemán Federico Nietzsche en Europa, y en Hispanoamérica tuvo a Vargas Vila como su gran divulgador. La importancia del suceso se debía a que era la condición de posibilidad para que el hombre ocupara ese lugar vacío. A través de la sobreexplotación de ese lugar, el nuevo tiempo de la Modernidad se impone sobre el de la sociedad tradicional fundamentada teocráticamente y teológicamente. Este acontecimiento es uno de los de mayor importancia en el proceso de secularización definida por Gutiérrez Girardot como el "proceso por el cual partes de la sociedad y trozos de su cultura han sido liberados del dominio de las instituciones y símbolos religiosos" (Heterodoxias 23). A través de su escritura Vargas Vila reivindica con insistencia un horizonte ausente de Dios, ya que desde su punto de vista su presencia en el infinito era la mejor justificación de las religiones que se otorgaban el derecho de hablar en su nombre. Vargas Vila sugirió en repetidas ocasiones que el hombre debía prescindir plenamente de la imagen de Dios para poder explotar plenamente la potencia de ese nuevo espacio abandonado por la divinidad. Con este deplazamiento el autor reivindicó un pleno ateísmo, pues de esa ausencia de Dios dependían las nuevas relaciones entre los hombres. Aunque Rafael Gutiérrez Girardot ha planteado que en Hispanoamérica "la muerte de Dios" significó crisis religiosa, la gran excepción de nuevo fue Vargas Vila:

En el mundo de lengua española, que con el Modernismo recuperó acontecimientos culturales europeos anteriores, y que por su tradición no pudo percibirlos con la hondura y el tormento con que el pensamiento alemán lo hizo, este acontecimiento de la "muerte de Dios" tuvo el carácter de "crisis religiosa", de pérdida de la fe, de duda religiosa, de temor del ateísmo. (Gutiérrez Girardot, Modernismo 53)

Vargas Vila, más que perturbarlo este acontecimiento, lo propagó como buena nueva del fin de la divinidad. El autor explora este convencimiento con gran intensidad a través de su heterogénea obra. En la novela Las rosas de la tarde (1901), Hugo Vial medita sobre la problemática de muerte de Dios explicando que "la Conciencia humana sufre un eclipse. Dios ha muerto en las almas; / y el Mito, al desaparecer en las convulsiones de un dragón herido, tocándola con la punta de sus alas, desorbitó la Tierra; / y hubo la sombra..." (84). De igual manera Claudio, uno de los protagonistas de la novela Los parias, conversando con Georgina sobre la difícil situación en la que se encuentra su pueblo y su país, insiste sobre la ausencia de Dios:

¿No sientes algo como el rodar de carros apocalípticos en el horizonte? Es la guerra que viene. Ella será la libertadora ... / -Dios lo quiera. / -Dios, hermana mía no quema ya zarzas, ni detiene el sol, ni lanza lluvias de piedra, combatiendo por los hombres,

Revista Iberoamericana, Vol. LXXXI, Núm. 252, Julio-Septiembre 2015, 787-803 ISSN 0034-9631 (Impreso)

ISSN 2154-4794 (Electrónico) 
como en los poemas heroicos de la Biblia. Dios ha desaparecido de la Historia. No queda en pie, en ella, sino el hombre. (162-63)

El acontecimiento decimonónico de la "muerte de Dios" fue divulgado por Vargas Vila en la sociedad finisecular hispanoamericana a través de la proliferación de héroes que asumían un pleno ateísmo, que para él era la actitud natural que todo hombre honesto debía asumir. Para Vargas Vila el ateísmo era el camino que conducía hacia la libertad. En este sentido, el narrador omnisciente de la novela El minotauro (1916) reflexiona que "después que hemos sacudido la tiranía de Dios, ya ninguna otra tiranía puede reinar sobre nuestro espíritu; / sólo el Hombre Ateo, es Hombre libre; / y, para ser libre, se hizo Ateo" (43).

Finalmente, sólo nos queda resaltar que la escritura de Vargas Vila, a pesar de las debilidades que dan cuenta del costo que implica generar una obra en circunstancias adversas, logra como pocas en la Hispanoamérica finisecular configurar un campo intelectual, diferente al político y al social. Frente a las diversas leyendas que se han tejido sobre el escritor colombiano, algún mortal desprevenido podría preguntar: ¿Pero, al fin de cuentas quién es Vargas Vila? A lo cual habría que responder categóricamente diciendo que Vargas Vila, es simplemente un intelectual. Ese lugar en la historia de Hispanoamérica lo conquistó a través del ejercicio de una escritura comprometida con la sociedad de su tiempo. He ahí una actitud plenamente moderna.

\section{OBRAS CITADAS}

Arciniegas, Germán. Prólogo. Aura o las violetas, Emma, Lo irreparable, Flor de fango. José María Vargas Vila. Bogotá: Círculo de Lectores, 1984.

Barthes, Roland. El placer del texto; seguido por Lección inaugural. Nicolás Rosa y Oscar Terán, trads. México: Siglo XXI, 1995.

Baudelaire, Charles. Obras. Nydia Lamarque, trad. Madrid: Aguilar, 1963.

Borges, Jorge Luis. Historia de la eternidad. Madrid: Alianza Editorial, 1988.

Botero, Ebel. "Un hombre en blanco y negro: Vargas Vila". Boletín Culturaly Bibliográfico 8/5 (1965): 671-674.

Bourdieu, Pierre. Las reglas del arte. Génesis y estructura del campo literario. Thomas Kauf, trad. Barcelona: Anagrama,1995.

Darío, Rubén. La vida de Rubén Darío escrita por él mismo. 1921. Caracas: Biblioteca Ayacucho, 1991.

Deas, Malcolm D. Del poder y la gramática: y otros ensayos sobre historia, política y literatura colombianas. Madrid: Taurus, 2009.

Deleuze, Gilles y Félix Guattari. Milmesetas: capitalismo y esquizofrenia. José Vásquez Pérez y Umbelina Larraceleta, trads. Valencia: Pre-textos, 1980.

Revista Iberoamericana, Vol. LXXXI, Núm. 252, Julio-Septiembre 2015, 787-803 ISSN 0034-9631 (Impreso) 
Enciso, Luis Miguel. La Europa del siglo XVIII. Barcelona: Ediciones Península, 2001. Escobar Uribe, Arturo. El divino Vargas Vila. Santa Fe de Bogotá: Gráficas Venus, 1968. Foucault, Michel. Estética, ética y hermenéutica. Ángel Gabilondo Pujol, trad. Barcelona: Paidós, 2001.

Vigilar y castigar: nacimiento de la prisión. 1975. Aurelio Garzón del Camino, trad. México: Siglo Veintiuno, 1997.

Gutiérrez Girardot, Rafael. Modernismo: supuestos históricos y culturales. Bogotá: Fondo de Cultura Económica. 1987. Heterodoxias. Bogotá: Taurus, 2004.

Jiménez, Juan Ramón. "El modernismo poético en España y en Hispanoamérica. El modernismo". Lily Litvak, ed. Madrid: Taurus, 1981. 227-241.

Kant, Immanuel. Contestación a la pregunta: ¿Qué es la Ilustración? Consejo Superior de Investigaciones Científicas - Consejo Superior de Investigaciones Científicas, 2001. 25 sept. 2013. <http://isegoria.revistas.csic.es/index.php/isegoria/article/ view/595/596>.

Martí, José. Obras completas. Vol. 20. Epistolario. La Habana: Editorial Nacional de Cuba, 1965.

Nietzsche, Federico. Crepúsculo de los ídolos. 1889. Andrés Sánchez Pascual, trad. Madrid: Alianza Editorial, 2000.

Noguera Mendoza, Aníbal. “José María Vargas Vila”. Manual de literatura colombiana. Tomo I. Bogotá: Instituto Colombiano de Cultura, 1982. 303-336.

Oviedo, José Miguel. Historia de la literatura hispanoamericana. Tomo 2. Del Romanticismo al Modernismo. Madrid: Alianza Editorial, 1997.

Restrepo, Luis Antonio. "Literatura y pensamiento 1946-1957". Nueva Historia de Colombia. Bogotá: Planeta, 1989.

Sierra Mejía, Rubén. Ensayos filosóficos. Bogotá: Instituto Colombiano de Cultura, 1978. Vargas Vila, José María. Ars Verba. Barcelona: Ramón Sopena, 1921. De los viñedos de la eternidad. Barcelona: Ramón Sopena, 1916. Del rosal pensante. París: Librería de la Vda. de Bouret, 1914. Diario secreto. Selección, introducción y notas de Consuelo Triviño. Bogotá: Arango Editores, Ancora Editores, 1989. El Minotauro. Barcelona: Ramón Sopena, 1916. Huerto agnóstico. París: Vda. de Bouret, 1912. Las rosas de la tarde. París: Librería de la Vda. de Bouret, 1910. Laureles rojos. París: Librería Americana, 1909. Los Césares de la decadencia. París: Librería Americana, 1907. Los Divinos y los Humanos. París: Librería Americana, 1903. Los estetas de Teópolis. Madrid: Librería de Antonio Rubiños, 1918. Los parias. Valencia: Biblioteca "Fénix", 1903. 
Rubén Darío. México: Medina Hermanos, 1968.

Vargas Vila: sufragio, selección, epitafio. Malcolm D. Deas, ed. Bogotá: Fondo de Promoción de la Cultura del Banco Popular, 1984.

Vidales, Luis. "Iniciación al estudio crítico sobre José María Vargas Vila". Boletín Cultural y Bibliográfico 8/5 (1965): 666-670.

Williams, Raymond L. Novela y poder en Colombia, 1844-1987. Bogotá: Tercer Mundo Editores, 
